Pesq. Vet. Bras. 35(5):391-395, maio 2015 DOI: $10.1590 / \mathrm{S} 0100-736 \mathrm{X} 2015000500001$

\title{
Investigação epidemiológica de Estomatite vesicular por achados clínicos em bovinos e equinos no Estado do Maranhão ${ }^{1}$
}

\author{
Roberto C.N. de Arruda², José M.F. Segundo ${ }^{3}$, Bruno A. Soares ${ }^{4}$, Nelson R.S. \\ Martins $^{4}$, Thales A. Barçante ${ }^{5 *}$ e Joziana M.P. Barçante ${ }^{5}$
}

\begin{abstract}
Arruda R.C.N., Segundo J.M.F., Soares B.A., Martins N.R.S., Barçante T.A. \& Barçante J.M.P. 2015. [Stomatitis vesicular in cattle and horse in the Maranhão state.] Investigação epidemiológica de Estomatite vesicular por achados clínicos em bovinos e equinos no Estado do Maranhão. Pesquisa Veterinária Brasileira 35(5):391-395. Laboratório de Biologia Parasitária, Setor de Medicina Veterinária Preventiva, Departamento de Medicina Veterinária, Universidade Federal de Minas Gerais, Campus Universitário, Lavras, MG 37200-000, Brazil. E-mail: tbarcante@gmail.com

Vesicular stomatitis (VS) is an infectious viral disease that affects bovines, equines, swine, wild animals and humans. As it is indistinguishable from other vesicular diseases, mainly Foot and Mouth Disease (FMD), it causes restrictions in commercial livestock trade at national and international levels and also significant economic losses. As the epidemiology and maintenance of VS virus in nature are not clearly understood it is difficult to take effective control measures. VS was diagnosed in some regions of Brazil, such as Minas Gerais, Santa Catarina, São Paulo and Alagoas. Cattle and horses with clinical symptoms of drooling, shedding of the lingual epithelium, presence of vesicles on the oral mucosa were observed and reported to the National Animal Health Office health of Maranhão State, Brazil. Samples of serum of these animals were collected and sent to Laboratório Nacional de Agropecuaria for ELISA and virus neutralization and differential diagnosis for Foot and Mouth Disease (FMD). The results of ELISA confirmed the VS. In the differential diagnosis, the results were negative for FMD. Samples of bovine epithelial tissue for VS by PCR confirmation of diagnosis were collected and sent to Biological Institute of São Paulo. Molecular results confirmed the Vesiculovirus Indiana III (Alagoas/VSAV) infection.
\end{abstract}

INDEX TERMS: Vesiculovirus, vesicular stomatitis, foot and mouth disease, equine, bovine, Brazil.

RESUMO.- A Estomatite Vesicular (EV) é uma doença infecciosa que acomete equinos, bovinos, suínos, mamíferos silvestres e humanos. Por apresentar sinais clínicos seme-

\footnotetext{
${ }^{1}$ Recebido em 22 de julho de 2014

Aceito para publicação em 19 de novembro de 2014.

${ }^{2}$ Superintendência Federal de Agricultura, Pecuária e Abastecimento no Estado do Maranhão (SFA/MA-MAPA). Praça da República 147, Diamante, São Luis, MA 65.020-500, Brasil. E-mail: rcnegreiros.arruda@gmail.com

${ }^{3}$ Agência de Defesa Agropecuária do Maranhão (AGED-MA), Travessa 7 de setembro 120, Centro, Porto Franco, MA 5970.000, Brasil.

${ }^{4}$ Laboratório de Doenças das Aves, Escola de Veterinária (EV), Universidade Federal de Minas Gerais (UFMG), Av. Presidente Antônio Carlos 6627, Campus Pampulha, Belo Horizonte, MG 31270-901, Brasil. E-mails: nrsmartins@gmail.com, brunoantunes.soares@yahoo.com.br

${ }^{5}$ Laboratório de Biologia Parasitária (Biopar), Departamento de Medicina Veterinária Preventiva (DMV), Universidade Federal de Lavras (UFLA), Lavras, MG 37200-000, Brasil. E-mails: joziana@dmv.ufla.br, *Autor para correspondência: tbarcante@gmail.com
}

lhantes a outras doenças vesiculares, principalmente, febre aftosa, sua presença em determinadas regiões pode interferir no intercâmbio comercial internacional dos animais, seus produtos e subprodutos. Apesar de sua importância, a epidemiologia e a manutenção do vírus no ambiente não estão totalmente esclarecidas dificultando a aplicação de medidas de controle efetivas. A doença já foi diagnosticada em todas as regiões brasileiras. Bovinos com sialorréia, perda do epitélio lingual, lesões abertas com bordas amareladas nas gengivas, lábios, língua e mucosa oral e equinos com sialorréia e lesões abertas na mucosa oral e lábios foram observados e notificados ao Serviço Veterinário Oficial do Estado do Maranhão, Agência Estadual de Defesa Agropecuária do Maranhão (AGRD/MA). Amostras de soro de equinos e bovinos com sintomas de EV foram coletadas para investigação por ELISA e por neutralização viral, além do diagnóstico diferencial para Febre Aftosa (FA). Frag- 
mentos epiteliais de bovinos com lesões na língua foram coletados para identificação molecular do agente. Todos os animais foram negativos para FA. Todos os bovinos e equinos foram reativos para EV nos testes sorológicos. A partir dos fragmentos epiteliais de bovinos enviados ao Instituto Biológico de São Paulo para PCR, foi possível caracterizar o agente como Vesiculovirus Indiana III (Alagoas/VSAV).

TERMOS DE INDEXAÇÃO: Vesiculovirus, estomatite vesicular, febre aftosa, equinos, bovinos, Brasil.

\section{INTRODUÇÃO}

A Estomatite Vesicular (EV) é uma doença infecciosa causada por um RNA-vírus, pertencente à Família Rhabdoviridae, gênero Vesiculovirus; existem dois tipos imunologicamente distintos do vírus da EV, classificados como New Jersey (NJ) e Indiana, sendo esse último classificado em três subtipos: Indiana Clássica (Indiana I), COCAL (Indiana II) e VSAV (Indiana III / Alagoas), sendo que o víruse acomete principalmente bovinos e equinos, mas suínos, mamíferos silvestres e humanos também são susceptíveis a infecção (De Stefano et al. 2003, Lichty et al. 2004, Brasil 2012, Ferris et al. 2012,). A infecção pode ocasionar lesões vesiculares e ulcerações nos lábios, língua, mucosa oral, narinas, tetos e bordas coronárias dos cascos, reduzindo o consumo de alimentos e água, o que acarreta perda de peso e diminuição na produtividade (Letchworth et al. 1999, Perez et al. 2010).

A Estomatite Vesicular é uma enfermidade restrita ao Hemisfério Ocidental, entretanto existem relatos da enfermidade na África do Sul, em cavalos, que datam do século XIX (1884 e 1887). Após esse episódio, não houve mais notificações da doença nesta localidade ou em nenhuma outra parte da África. É mais provável que sempre tenha estado presente nas Américas e que em algum momento possa ter sido levado para a África (Hanson 1952).

No Brasil, o primeiro caso foi registrado em equinos em 1964, esta amostra sendo classificada como Indiana III (Alagoas) no estado de Alagoas (Andrade et al. 1980). Dois anos depois, também no estado de Alagoas, o serviço veterinário brasileiro registrou um surto da doença em muares. De 2005 a 2013, houve 169 focos registrados nos estados da Bahia, Ceará, Goiás, Pernambuco, Maranhão, Mato Grosso, Minas Gerais, Pará, Paraíba, Piauí, Rio Grande do Norte, Rio de Janeiro, São Paulo e Tocantins. Foram registrados 16 focos em 2011; um em 2012; 55 em 2013 e em 2014 foram registrados 54 até o momento (Brasil 2014).

Atualmente a enfermidade apresenta atividade endêmica do norte da América do Sul ao norte do México e sudeste dos Estados Unidos. Atividade epidêmica geralmente acorre no sul da América do Sul, Estados Unidos e Canadá (Arboleda \& Trujillo 2002).

0 modo pelo qual o vírus é mantido no ambiente durante os surtos e a forma de transmissão não estão totalmente esclarecidos. Sabe-se que a transmissão pode ocorrer por contato direto de animais infectados com animais saudáveis, fômites como água contaminada, alimentos e equipamentos de ordenha, ingestão de vegetais infectados e transmissão vetorial por algumas espécies de culicídeos e psicodídeos (Zimmer et al. 2013).
Segundo Perez et al. (2010), a EV embora se apresente com baixos níveis de morbidade e mortalidade, tem impacto econômico direto na produção animal. Devido a semelhança clínica coma Febre Aftosa (FA), o comércio e trânsito de animais são restringidos em áreas com suspeita de EV, até que haja confirmação do diagnóstico laboratorial definitivo, que é feito por ELISA e PCR (De Stefano et al. 2003, Fernández et al. 2008).

Tendo em vista se tratar de uma doença que é diagnóstico diferencial para FA, é relevante a caracterização de novas áreas de ocorrência da EV. Assim, o objetivo do presente relato foi descrever a realização da investigação epidemiológica e confirmação do caso provável de doença vesicular, assim como as medidas que devem ser adotadas pelo serviço veterinário oficial, num foco de estomatite vesicular.

\section{MATERIAL E MÉTODOS}

Localizado no oeste da região nordeste do Brasil, o Maranhão tem como limites, ao norte o Oceano Atlântico, a leste o estado do Piauí, a sul e sudeste o estado do Tocantins e o do Pará, a oeste. O estado ocupa uma área de $331.983,293 \mathrm{~km}^{2}$, sendo o segundo maior estado da Região Nordeste e o oitavo maior estado do Brasil. Com um plantel de 7.264.106, o Maranhão se consolida como detentor do nono maior rebanho de bovinos do país e o segundo do Nordeste (IBGE 2012). Com relação aos equinos, o rebanho seria de 173.739; muares: 100.190; e asininos: 102.203 (IBGE 2012).

A investigação epidemiológica teve início na Fazenda Ypê, no município de Porto Franco, MA, em dezembro de 2013; a propriedade foi caracterizada predominantemente pela exploração leiteira, cercada por matas densas, curso de água e com presença de animais silvestres, principalmente bandos de macacos-pregos (Cebus apela). Para os animais que apresentavam sialorréia, inicialmente o diagnóstico foi intoxicação por plantas tóxicas, assim que o Serviço Veterinário Oficial (SVO) foi notificado por denuncia, o atendimento deu-se dentro de $12 \mathrm{~h}$, contando-se que a enfermidade estaria em progressão a pelo menos uma semana. Foi realizado exame clínico em 106 animais, sendo 83 bovinos, quatro ovinos, 12 suínos, seis equinos e um asinino. A propriedade em questão apresentava sete bovinos e quatro equinos com sinais clínicos de doença vesicular.

Amostras do epitélio dos bovinos adultos com sialorréia e descamação do epitélio lingual foram coletadas utilizando tesoura de ponta romba e pinça estéril. Os fragmentos de tecido foram colocados em frasco de boca larga (coletor universal), estéril, previamente identificado com o nome da propriedade e tipo de epitélio (oral) e contendo líquido de Valleé em quantidade suficiente para que as amostras ficassem submersas. Os frascos foram desinfetados externamente e encaminhados primeiramente para o Laboratório Nacional Agropecuário, do Ministério da Agricultura, Pecuária e Abastecimento (LANAGRO, Pedro Leopoldo, MG) e posteriormente ao Instituto Biológico de São Paulo, em caixa isotérmica contendo bolsas de gelo para confirmação diagnóstica molecular pelo método de reação de cadeira em polimerase por transcrição reversa (RT-PCR). Devido à ausência de epitélio descamado, não foi realizada coleta de tecido nos equinos sintomáticos.

Adicionalmente, amostras de soro foram coletadas de todos os bovinos (sete animais) da propriedade que apresentassem alterações clínicas compatíveis com Estomatite vesicular (EV) ou Febre aftosa (FA) e de quatro equinos que apresentavam sinais clínicos evidentes. A coleta foi realizada utilizando sistema "vacutainer", através da sangria da veia jugular. As amostras foram 
encaminhadas para Laboratório de Diagnóstico de Doenças Virais (LDDV- LANAGRO), em caixa isotérmica com bolsas de gelo para confirmação diagnóstica de febre aftosa pelo método de I-ELISA 3ABC (MET/LDDV/PL/029 V.1), e para exame detecção de anticorpos para o vírus da estomatite vesicular por soroneutralização para os subtipos Indiana I, II e III (MET/LDDV/PL/023 V.3).

Após a coleta do material, foi realizada vigilância ativa, com avaliação clínica de todos os animais do rebanho, com intervalos de três dias. Após 15 dias foi realizada uma segunda coleta de soro (pareada), seguindo o preconizado em Brasil (2012) seguindo o mesmo protocolo citado anteriormente.

Considerando o diagnóstico diferencial para FA, imediatamente após a coleta do material biológico foi feita, por parte do Serviço Veterinário Oficial, a suspensão preventiva da movimentação de animais da propriedade investigada e das propriedades circunvizinhas até a confirmação diagnóstica. Foi determinada a área de risco epidemiológico com um raio de 10 $\mathrm{km}$ a partir do foco inicial, incluindo a interdição de nove propriedades circunvizinhas, segundo as normas preconizadas por Brasil (2012).

A partir da demarcação da área de risco foi feita uma investigação epidemiológica nas nove propriedades localizadas dentro do raio de segurança. Foi feita a avaliação clínica abordando principalmente bocas, patas e tetos, em 877 animais, sendo 734 bovinos, 73 ovinos, 22 suínos, 46 equinos e 2 muares, onde não se observou nenhum animal com sintomatologia para enfermidades vesiculares. As ações que envolvem a vigilância ativa assim como e educação sanitária voltada para saúde foram realizadas em todas as propriedades da área de risco epidemiológico com intervalos de sete dias.

\section{RESULTADOS}

Durante a avaliação clínica, verificou-se que sete dos 83 bovinos da propriedade apresentavam sinais sugestivos de doença vesicular sendo duas fêmeas de 25 a 36 meses e cinco com mais de 36 meses, estas com bezerro ao pé, embora nenhum dos bezerros apresentasse sinais ou lesões. Os adultos sintomáticos apresentaram sialorréia, apatia, aumento da temperatura corporal (em média $38,5^{\circ} \mathrm{C}$ ), emagrecimento moderado ou caquexia, além de lesões nos lábios, gengivas, língua e mucosa oral, em todos os animais sintomáticos.

No exame clínico dos equinos, quatro dos seis animais apresentaram alterações clínicas sugestivas de doença vesicular: sialorréia, descamação na região das narinas e lábios. No teste de soroneutralização, todas as amostras de soro encaminhadas ao LANAGRO foram reativas para o $\mathrm{Ve}$ siculovirus e não reativas para febre aftosa (FA) conforme apresentado no Quadro 1. Os resultados pareados de soroconversão encontram-se detalhados no Quadro 2. 0 asinino não apresentou qualquer alteração.

As amostras de epitélio lingual de sete bovinos submetidas a RT-PCR foram consideradas positivas para o vírus da EV subtipo Indiana III e negativas para os subtipos Indiana I e Indiana II. Todas as amostras de soro foram não reativas para FA (Quadro 3) e reativas para o Vesiculovírus (Quadro $3)$.

Após a segunda coleta de soro pareado, verificou-se que três bovinos apresentaram soroconversão, com resultados de títulos até quatro vezes mais elevados, quando comparado com os resultados da primeira coleta (Quadro 4).
Quadro 1. Resultados dos exames de ELISA para febre aftosa e soroneutralização de equinos com suspeita de Estomatite Vesicular, realizados no Laboratório Nacional Agropecuário de Pedro Leopoldo, Minas Gerais

\begin{tabular}{|c|c|c|c|}
\hline \multirow[t]{3}{*}{ Amostra } & \multicolumn{2}{|c|}{ Títulos de anticorpos contra o vírus da $\mathrm{EV}^{\mathrm{a}}$} & \multirow{3}{*}{$\begin{array}{c}\text { ELISA } \\
\text { para FA }\end{array}$} \\
\hline & Indiana I & Indiana II & \\
\hline & $\mathrm{C} 1^{\mathrm{c}}$ & C1 & \\
\hline
\end{tabular}

\begin{tabular}{llllllll}
\hline Equino 1 & $\mathrm{R}^{\mathrm{e}}(1,6)$ & $\mathrm{R}(2,2)$ & $\mathrm{R}(1,9)$ & $\mathrm{R}(2,5)$ & $\mathrm{R}(>=3,4)$ & $\mathrm{R}(>=3,4)$ & $\mathrm{NR}^{\mathrm{f}}$
\end{tabular}

Equino $2 \quad \mathrm{R}(1,9) \quad \mathrm{R}(1,6) \quad \mathrm{R}(2,2) \quad \mathrm{R}(2,5) \quad \mathrm{R}(>=3,4) \mathrm{R}(>=3,4) \quad \mathrm{NR}$ Equino 3 NR $(<1,3) \quad R(1,9) \quad R(2,5) \quad R(2,2) \quad R(>=3,4) \quad R(>=3,4) \quad N R$ Equino $4 \quad \mathrm{R}(2,5) \quad \mathrm{R}(1,9) \quad \mathrm{R}(1,9) \quad \mathrm{R}(2,2) \quad \mathrm{R}(>=3,4) \quad \mathrm{R}(>=3,4) \quad \mathrm{NR}$

${ }^{\mathrm{a}} \mathrm{EV}=$ Estomatite vesicular, ${ }^{\mathrm{b}} \mathrm{FA}=$ febre aftosa, ${ }^{\mathrm{c}} \mathrm{C} 1=$ primeira coleta, ${ }^{\mathrm{d}} \mathrm{C} 2$ = segunda coleta, ${ }^{\mathrm{e}} \mathrm{R}=$ reagente,${ }^{\mathrm{f}} \mathrm{NR}=$ não reagente .

Quadro 2. Resultados da soroconversão pareada de eqüinos com suspeita de Estomatite Vesicular, realizados no Laboratório Nacional Agropecuário de Pedro Leopoldo, Minas Gerais, por soroneutralização

\begin{tabular}{lccccccccc}
\hline Amostra & \multicolumn{6}{c}{ Títulos de anticorpos contra o vírus da EV } \\
\cline { 2 - 10 } & \multicolumn{3}{c}{ Indiana I } & \multicolumn{4}{c}{ Indiana II } & \multicolumn{3}{c}{ Indiana III } \\
\cline { 2 - 10 } & C1 $^{\mathrm{a}}$ & $\mathrm{C}^{\mathrm{b}}$ & $\mathrm{SC}^{\mathrm{c}}$ & $\mathrm{C} 1$ & $\mathrm{C} 2$ & $\mathrm{SC}$ & $\mathrm{C} 1$ & $\mathrm{C} 2$ & $\mathrm{SC}$ \\
\hline Equino 1 & 158,49 & 39,81 & 0,25 & 158,49 & 316,23 & 2 & 2511,89 & 2511,89 & 1 \\
Equino 2 & 39,81 & 79,43 & 2,00 & 316,23 & 316,23 & 1 & 2511,89 & 2511,89 & 1 \\
Equino 3 & 79,43 & 19,95 & 0,25 & 79,43 & 158,49 & 2 & 2511,89 & 2511,89 & 1 \\
Equino 4 & 79,43 & 316,23 & 3,98 & 19,95 & 158,49 & 7,94 & 2511,89 & 2511,89 & 1
\end{tabular}

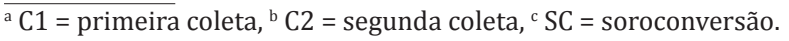

\section{DISCUSSÃO}

A propriedade alvo foi caracterizada predominantemente pela exploração leiteira, cercada por matas densas, curso de água e com presença de animais silvestres, principalmente bandos de Macacos-pregos (Cebus apela). No presente estudo, embora a propriedade investigada fosse mista, com criação de bovinos e equinos, suínos, ovinos e asininos, confirmou-se a infecção somente em bovinos e equinos. De acordo com Ferris et al. (2012) embora vários mamíferos sejam suscetíveis a infecção pelo Vesiculovirus, bovinos e equinos são aqueles na qual a Estomatite Vesicular (EV) é relatada com maior frequência, sendo que o percentual de animais clinicamente afetados varia de 5 a $10 \%$ podendo chegar a $80 \%$ em rebanhos leiteiros. No presente trabalho, verificou-se que $8,4 \%$ ou seja sete dos 83 dos bovinos estavam infectados, corroborando o achado dos autores. Com relação aos equinos, quatro dos seis animais, ou seja $66,7 \%$ apresentaram sintomatologia marcante e diagnóstico confirmado para EV.

Rodriguez (2002) relata que a EV é endêmica na Colômbia, Venezuela, Equador, Peru e sul do México. Casos esporádicos ocorrem no Brasil e na Argentina com os subtipos Indiana II e Indiana III. No Brasil, a EV foi relatada nos estados de Minas Gerais, São Paulo, Alagoas, Ceará e Santa Catarina (De Stefano et al. 2003). Na América Central e do Sul a EV ocorre durante todo o ano, embora tenha aumento no número de focos nos períodos de março a junho (Brasil 2012). No presente trabalho a enfermidade foi diagnosticada no mês de dezembro, época caracterizada com o início do período chuvoso, e consequentemente com alta proliferação de insetos hematófagos. Embora ainda não sejam completamente esclarecidos os mecanismos de transmissão do vírus, Rodriguez (2002) e Brasil (2012) apontam 


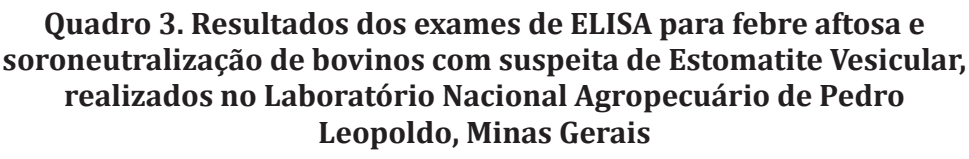

\begin{tabular}{|c|c|c|c|c|c|c|c|}
\hline \multirow[t]{3}{*}{ Amostra } & \multicolumn{6}{|c|}{ Títulos de anticorpos contra o vírus da EV } & \multirow{3}{*}{$\begin{array}{r}\text { ELISA } \\
\text { para FA }\end{array}$} \\
\hline & \multicolumn{2}{|c|}{ Indiana I } & \multicolumn{2}{|c|}{ Indiana II } & \multicolumn{2}{|c|}{ Indiana III } & \\
\hline & $\mathrm{C}^{\mathrm{c}}$ & $\mathrm{C} 2^{\mathrm{d}}$ & C1 & $\mathrm{C} 2$ & C1 & $\mathrm{C} 2$ & \\
\hline 1 & $\mathrm{NR}^{\mathrm{e}}(<1,3)$ & $\mathrm{NR}(<1,3)$ & NR $(<1,3)$ & NR $(<1,3)$ & $\mathrm{R}(2,2)$ & $\mathrm{R}(1,9)$ & $\mathrm{NR}^{\mathrm{f}}$ \\
\hline Bovino 2 & NR $(<1,3)$ & $\mathrm{R}(1,3)$ & $R(1,6)$ & NR $(<1,3)$ & $\mathrm{R}(1,9)$ & $\mathrm{R}(3,1)$ & NR \\
\hline Bovino 3 & $N R(<1,3)$ & $\mathrm{R}(1,3)$ & $\mathrm{R}(1,3)$ & $\operatorname{NR}(<1,3)$ & $\mathrm{NR}(<1,3)$ & $R(3,1)$ & NR \\
\hline Bovino 4 & $N R(<1,3)$ & $\operatorname{NR}(<1,3)$ & $\mathrm{NR}(<1,3)$ & $\operatorname{NR}(<1,3)$ & $\mathrm{R}(1,6)$ & $R(2,8)$ & NR \\
\hline Bovino 5 & NR $(<1,3)$ & NR $(<1,3)$ & $\mathrm{R}(1,3)$ & NR $(<1,3)$ & $\mathrm{R}(2,5)$ & $\mathrm{R}(2,8)$ & NR \\
\hline Bovino 6 & NR $(<1,3)$ & NR $(<1,3)$ & $R(1,6)$ & $\mathrm{R}(2,2)$ & $\mathrm{R}(3,1)$ & $\mathrm{R}(3,1)$ & NR \\
\hline Bovino 7 & NR $(<1,3)$ & $\mathrm{NR}(<1,3)$ & R $(1,9)$ & $\mathrm{R}(1,9)$ & $\mathrm{R}(2,5)$ & $R(2,5)$ & NR \\
\hline
\end{tabular}

a $\mathrm{EV}=$ Estomatite vesicular, ${ }^{\mathrm{b}} \mathrm{FA}=$ febre aftosa, ${ }^{\mathrm{c}} \mathrm{C} 1=$ primeira coleta, ${ }^{\mathrm{d}} \mathrm{C} 2=$ segunda coleta, ${ }^{\mathrm{e}} \mathrm{R}=$ reagente, ${ }^{\mathrm{f}} \mathrm{NR}=$ não reagente.

\begin{tabular}{|c|c|c|c|c|c|c|c|c|c|}
\hline \multirow[t]{3}{*}{ Amostra } & \multicolumn{9}{|c|}{ Títulos de anticorpos contra } \\
\hline & \multicolumn{3}{|c|}{ Indiana } & \multicolumn{3}{|c|}{ Indiana } & \multicolumn{3}{|c|}{ Indiana 1} \\
\hline & $\mathrm{C} 1^{\mathrm{a}}$ & & $\mathrm{SC}^{\mathrm{c}}$ & $\mathrm{C} 1$ & C2 & S & C1 & C2 & SC \\
\hline & & & 1 & & & & & & \\
\hline & & & 1 & & 19, & & & & 15, \\
\hline & $C_{2}$ & 19, & 1 & & 19, & 1 & & & 63,1 \\
\hline & 99 & 19, & 1 & & 19, & 1 & & & 5,8 \\
\hline & & 19, & 1 & & 19,9 & 1 & 3 & 630 & 2 \\
\hline & & & 1 & & 39 & 0,25 & & 1 & 1 \\
\hline & 19,95 & 19,95 & 1 & 9,43 & 79,43 & 1 & 316,23 & 316,23 & \\
\hline
\end{tabular}

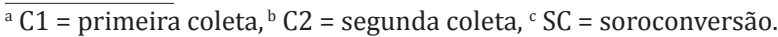

para a capacidade de diferentes espécies de insetos como flebotomíneos e simulídeos transportarem o Vesiculovirus e infectarem animais domésticos e o homem.

Devido a sua semelhança clínica com a febre aftosa (FA) em biungulados, os casos suspeitos de EV devem ser imediatamente notificados ao serviço veterinário oficial para diagnóstico diferencial de FA, investigação epidemiológica e adoção de medidas adequadas que evitem a propagação da doença. Dentre estas medidas, destaca-se a interdição das propriedades para impedir que os animais doentes deixem o local e possam ser tratados, evitando infecções secundárias em razão das lesões típicas da estomatite (Brasil 2014). Devido às restrições ao comércio nacional e internacional de animais e produtos pecuários, quarentenas e queda na produtividade dos animais acometidos, a EV é uma doença de importância econômica (Ferris et al. 2012). Contudo, em função da morbidade e mortalidade não serem significativas, em 2012, a Comissão do Código de Animais Terrestres da Organização Mundial da Saúde Animal (OIE) propôs a retirada da estomatite vesicular da lista de doenças. Assim, em 2014, foi aprovada a retirada da estomatite vesicular da lista de doenças da OIE (Brasil 2014).

A partir da suspeita inicial de doença vesicular, na Fazenda Ypê, foram implementadas ações de investigação e monitoramento nas propriedades da região circunvizinha, dentro de um Plano de Contingência contido no Sistema Brasileiro de Emergências Veterinárias, conforme recomendado por Brasil (2012). Os procedimentos realizados buscaram desenvolver a capacidade de notificação imediata e a pronta reação de todas as instâncias do sistema unificado de sanidade agropecuária, caso alguma propriedade adjacente também apresentasse animais positivos para EV. Nesse contexto, os animais suspeitos ficaram envolvidos nas fases de investigação e alerta, e medidas que restringiam a movimentação animal e os subprodutos foram estabelecidas. Após o período de monitoramento e análise, verificou-se que o foco com animais sintomáticos era restrito à propriedade investigada inicialmente.

Nos casos de suspeita de EV, o diagnóstico rápido e preciso é essencial, em função da similaridade com a FA. Testes como o ELISA e o isolamento do agente em célula Vero e PCR têm sido empregados (Sobestiansky 2002). No presente trabalho, as técnicas de diagnóstico utilizadas foram recomendadas por Fernández et al. (2008), De Stefano et al. (2003) e Brasil (2012).

Os resultados do exame de soroneutralização demonstraram reatividade dos soros dos equinos e dos bovinos com os três subtipos de Indiana (I, II e III). Contudo, tais resultados devem ser analisados com cautela, uma vez que o Brasil é considerado indene para o Indiana I e é conhecida a reatividade cruzada entre os subtipos (Brasil 2012). Considerando a ausência de epitélio para colheita de material destinado ao isolamento viral nos equinos, a confirmação do subtipo pode ser realizada somente para os isolados bovinos. Nestes últimos, foi possível a confirmação molecular definitiva para Indiana III (VSAV/Alagoas).

Os resultados encontrados nesse relato corroboram com López Inzaurralde et al. (1997) que citam os subtipos Indiana II e Indiana III, como responsáveis por casos esporádicos de EV no Brasil e na Argentina. No Brasil, a ocorrência do subtipo Indiana II caracteriza-se por surtos epidêmicos espaçados por longos períodos, com um intervalo de 12 anos sem registro, entre os anos de 1997 e 2011. Por outro lado, o vírus Indiana III tem sido relatado em diversos estados, com presença ativa, desde seu isolamento inicial (López Inzaurralde et al. 1997, Brasil 2012).

Em focos, é comum observar uma baixa prevalência clínica e uma elevada soroprevalência associada a uma variabilidade sorológica sem o clássico padrão de soroconversão (Brasil 2012). Embora seja considerado um parâmetro relativo, em três bovinos foi observada uma relação supe- 
rior a quatroentre a primeira e a segunda coletas pareadas. Estes dados reforçam a necessidade de uma continuidade da investigação epidemiológica na área do presente estudo, sobretudo nos equinos, nos quais não foi possível o isolamento do agente e houve sorologia positiva e soroconversão no exame para o subtipo Indiana I. Há necessidade de se investigar se tais resultados refletem uma soroconversão real ou uma reatividade cruzada, uma vez que esta é reconhecida entre os subtipos.

De 2005 a 2013 houve 169 focos registrados nos estados da Bahia, Ceará, Goiás, Pernambuco, Maranhão, Mato Grosso, Minas Gerais, Pará, Paraíba, Piauí, Rio Grande do Norte, Rio de Janeiro, São Paulo e Tocantins. Foram registrados 16 focos em 2011; 1 em 2012; 55 em 2013 e este ano 54 até o momento (Brasil 2014). Embora, a ocorrência de animais positivos no Maranhão já tenha sido relata por sorologia, esse é o primeiro relato da ocorrência de EV em bovinos e equinos no Estado, notificada pela observância de manifestações clínicas/exames laboratoriais e confirmada em bovinos pelo isolamento do agente. De acordo com López Inzaurralde et al. (1997) é difícil estabelecer conclusões definitivas sobre animais soropositivos sem correlação clínica, uma vez que é conhecida a existência de reações cruzadas com outros rabdovírus. Neste sentido o presente achado, no Estado do Maranhão, com manifestações clínicas associadas ao isolamento viral, amplia a caracterização epidemiológica da enfermidade no Brasil e contribui para o estabelecimento de medidas preventivas e de diagnóstico a essa região. Neste sentido, reforça-se o controle da dispersão do vírus pela restrição da movimentação de animais, instituição de quarentena para os doentes, busca de um rápido diagnóstico e controle de insetos vetores, com a eliminação ou redução dos criadouros, desinfecção do ambiente (currais e estábulos), além da notificação aos órgãos oficiais como medidas essenciais para o controle da doença.

Agradecimentos.- À Fundação de Amparo à Pesquisa do Estado de Minas Gerais (FAPEMIG). Nossos agradecimentos pelas contribuições de ações no episódio, aos colegas da AGED-MA, Adriano Mendes Moura, Amélia Soraya França Santana Freitas, Lauro de Queiroz Saraiva, Maria Cristina Cavalcante Dutra, Margarida Paula Carreira de Sá Prazeres, Rayanne Barros Moreira e Tereza Satiko Ueda Santos Wallinson Fernandes Camara Galdino.

\section{REFERÊNCIAS}

Andrade C.M., Rosas C.E.E., Amorim L.M., Mota J.P., Teixeira E.N. \& Santos N.F. 1980. Vesicular Stomatitis in Brazil I. Isolation and identification of the Alagoas strain. Annals Microbiol. 25:81-89.

Arboleda J.J. \& Trujillo C.M. 2002. La estomatitis vesicular: algunos aspectos históricos, clínicos, eco-epidemiológicos virológicos, de prevención y control. Revta Colombiana Ciencias y Pecuaria 15:356-367.

Brasil. Ministério da Agricultura, Pecuária e Abastecimento. Secretaria de Defesa Agropecuária. 2012. Definição de caso de Estomatite Vesicular e Fluxo de doença Vesiculares. Circular DSA no 155 de 31.08.12, MAPA, Brasília.

Brasil. Ministério da Agricultura, Pecuária e Abastecimento. 2014. MAPA orienta sobre a Estomatite vesicular. Disponível em <http://www.agricultura.gov.br/animal/noticias/2014/07/mapa-orienta-sobre-a-estomatite-vesicular> Acessado em 18 set. 2014.

De Stefano E., Araújo W.P., Passos E.C. \& Pituco E.M. 2003. Estomatite vesicular. Arqs Inst. Biológico, São Paulo, 69:127-133.

Fernández J., Montserrat A.M., Romeroa L., Sanchez C., Belák S., Arias M. \& Sánchez-Vizcaínno J.M. 2008. Rapid and differential diagnosis of footand-mouth disease, swine vesicular disease, and vesicular stomatitis by a new multiplex RT-PCR assay. J. Virol. Methods 147:301-311.

Ferris N.P., Clavijo A., Yangb M., Velazquez-Salinasc L., Nordengrahnd A., Hutchingsa G.H., Kristerssond T. \& Merzad M. 2012. Development and laboratory evaluation of two lateral flow devices for the detection of vesicular stomatitis virus in clinical samples. J. Virol. Methods 180:96100.

Hanson R.P. 1952. The natural history of vesicular stomatitis. Bacteriol. Revs 16: 179-204.

Letchworth G.J., Rodriguez L.L. \& Barrera J.D.C. 1999. Vesicular stomatitis. Vet. J. 157:239-260.

Lichty B.D., Power A.T., Stojdl D.F. \& Bell J.C. 2004. Vesicular stomatitis virus: re-inventing the bullet. Trends Mol. Med. 10(5):210-216.

López Inzaurralde A., Moreira E.C., López J.W. \& Söndahl M.S. 1997. Distribución histórica de la estomatitis vesicular em Brasil. Bolm Centra Panamericana Fiebre Aftosa 62/63:10-20.

Perez A.M., Pauszek S.J., Jimenez D., Kelley W.N., Whedbee Z. \& Rodriguez L.L. 2010. Spatial and phylogenetic analysis of vesicular stomatitis virus over-wintering in the United States. Prev. Vet. Med. 93:258-264.

Rodriguez L.L. 2002. Emergence and re-emergence of vesicular stomatitis in the United States. Virus Res. 85:211-219.

Sobestiansky J. 2002. Sistema intensivo de produção de suínos: programa de Biossegurança. 2ª ed. 0 Autor, Goiânia. 108p.

Zimmer B., Summermatter K. \& Zimmer G. 2013. Stability and inactivation of vesicular stomatitis virus, a prototype Rhabdovirus. Vet. Microbiol. 162:78-84. 